
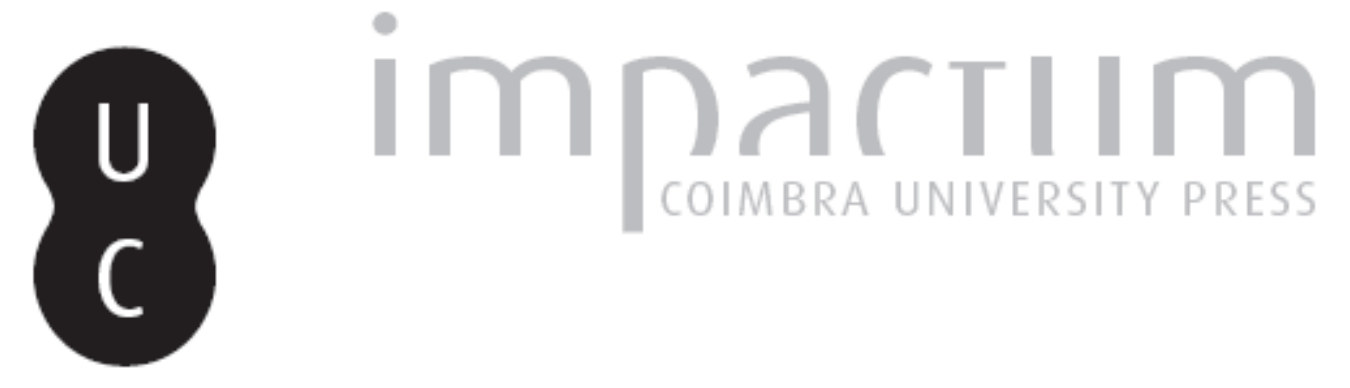

\title{
Renovação urbana do estaleiro da Lisnave em Almada
}

Autor(es): Dias, Manuel Graça; Vieira, Egas José

Publicado por: Editorial do Departamento de Arquitectura

URL persistente:

URI:http://hdl.handle.net/10316.2/37453

DOI:

DOI:http://dx.doi.org/10.14195/0874-6168_3_7

Accessed : $\quad$ 26-Apr-2023 12:16:20

A navegação consulta e descarregamento dos títulos inseridos nas Bibliotecas Digitais UC Digitalis, UC Pombalina e UC Impactum, pressupõem a aceitação plena e sem reservas dos Termos e Condições de Uso destas Bibliotecas Digitais, disponíveis em https://digitalis.uc.pt/pt-pt/termos.

Conforme exposto nos referidos Termos e Condições de Uso, o descarregamento de títulos de acesso restrito requer uma licença válida de autorização devendo o utilizador aceder ao(s) documento(s) a partir de um endereço de IP da instituição detentora da supramencionada licença.

Ao utilizador é apenas permitido o descarregamento para uso pessoal, pelo que o emprego do(s) título(s) descarregado(s) para outro fim, designadamente comercial, carece de autorização do respetivo autor ou editor da obra.

Na medida em que todas as obras da UC Digitalis se encontram protegidas pelo Código do Direito de Autor e Direitos Conexos e demais legislação aplicável, toda a cópia, parcial ou total, deste documento, nos casos em que é legalmente admitida, deverá conter ou fazer-se acompanhar por este aviso.

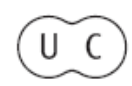




\section{ecdj $\quad z$}

fctuc|departamento de arquitectura

novos mapas para velhas cidades

guido giangregorio / walter rossa

rui lobo | álvaro domingues / nuno grande

joão paulo cardielos / josé antónio bandeirinha

workshop internacional de arquitectura

coimbra: um novo mapa [16 a 25 de novembro]

projectos

manuel graça dias margueira

manuel fernandes de sá marginal do douro antónio belém lima vila real

editores jorge figueira + nuno grande 


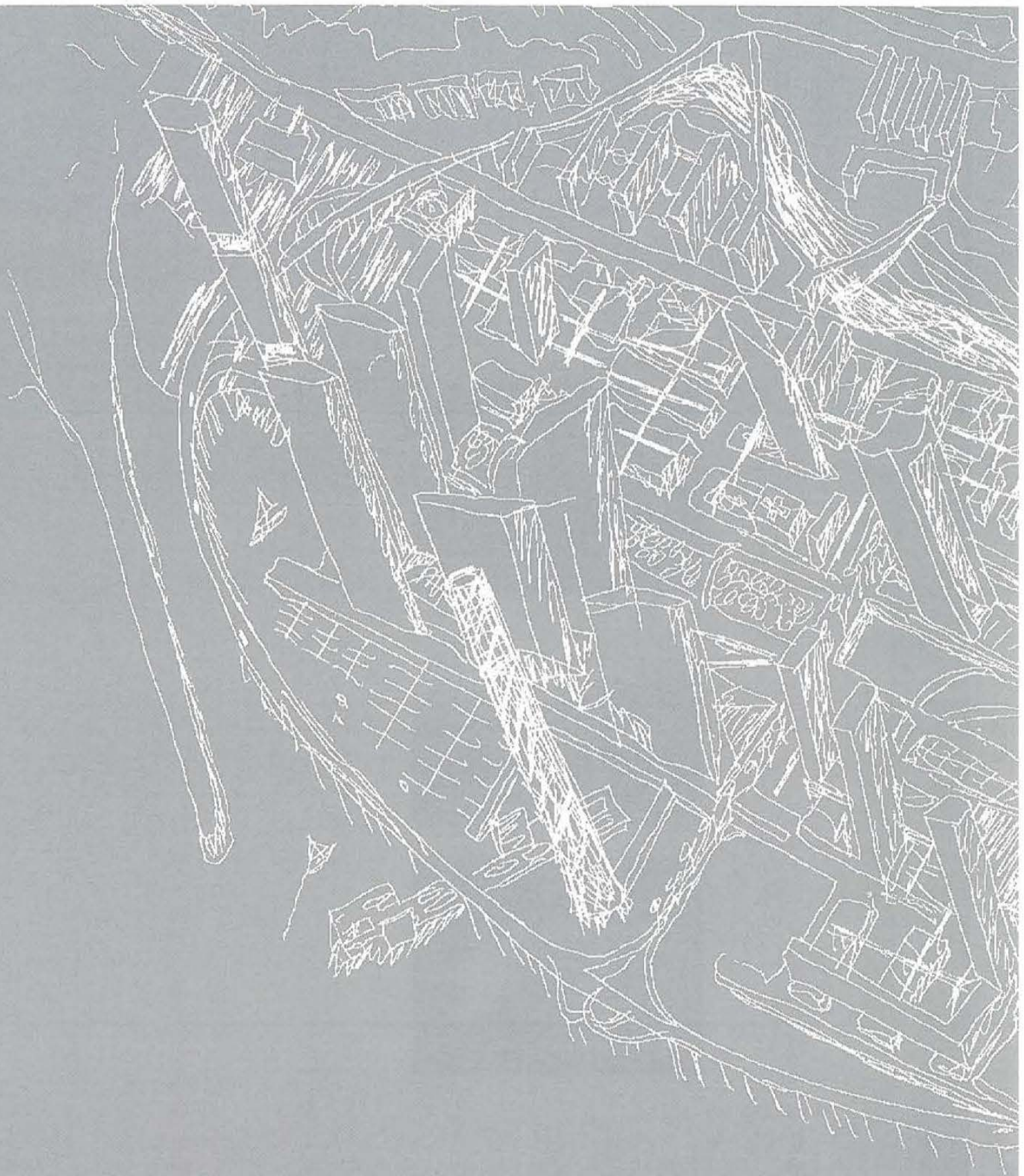




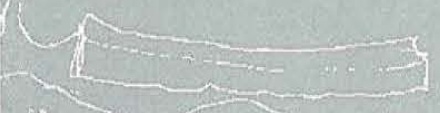
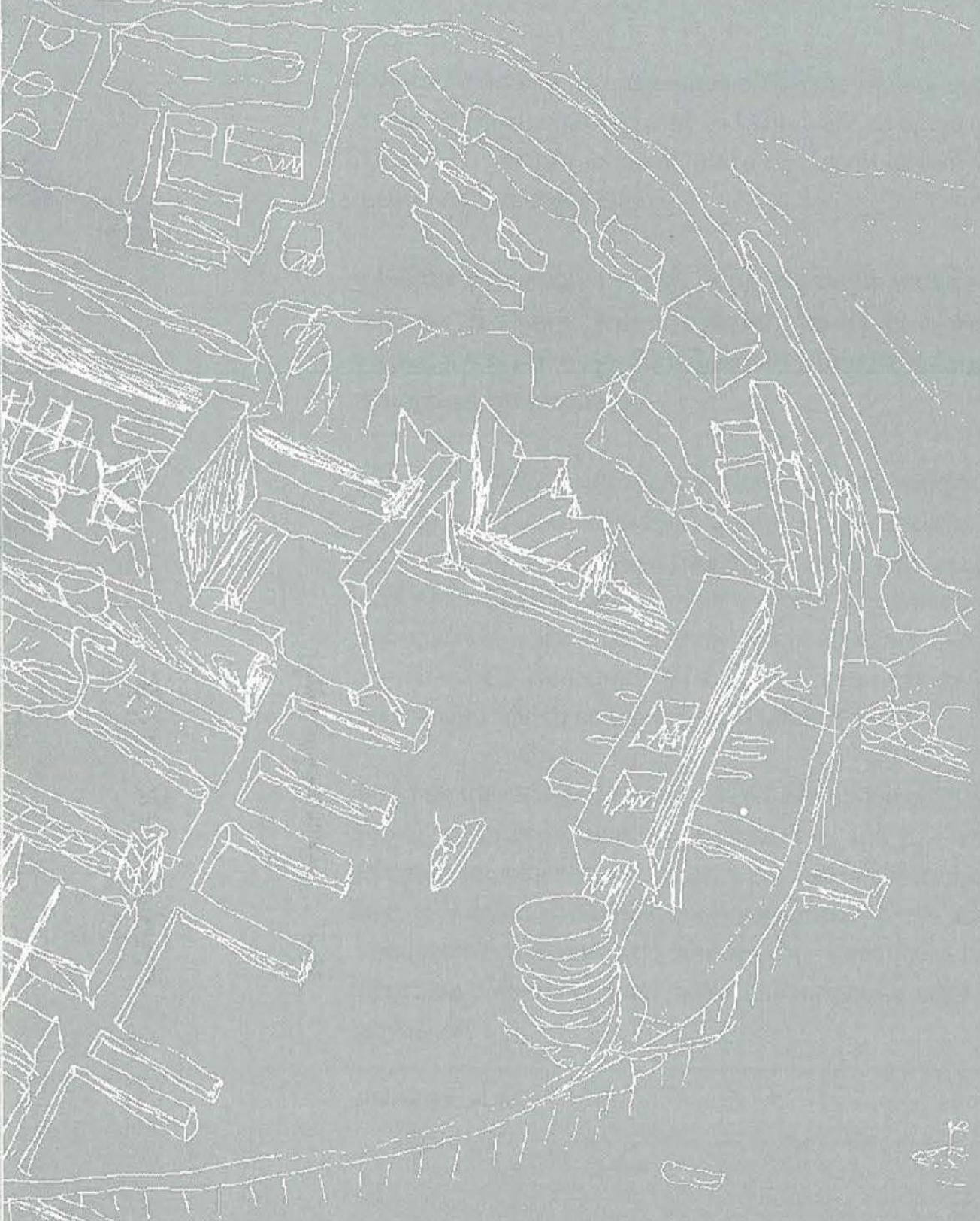

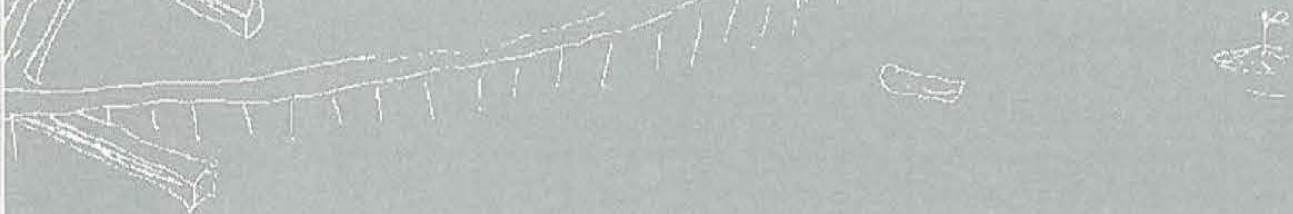

renovaça urbana do estaleiro da lisnave em almada 
Este tentou ser um ensaio de ocupação, tanto quanto possível inovador, do ponto de vista urbano, para os 49 hectares de aterro onde esteve instalado em pleno, até há poucos anos, o Estaleiro da Lisnave, na Margueira.

Uma elegante elipse desenha, sobre a água, um tabuleiro distributivo e panorâmico que "abraça" o novo sítio e o "segura" para o lado de Almada, entrelaçando-se, a norte e a sul, no emaranhado da cidade.

É sobre os pódiuns, cheios de atracções, sobreposições e desejo, que se levantam depois torres que espreitam Lisboa, que the olham a preguiça dos rebocos deitados ao sol, longos volumes de conventos marcando as colinas distantes. Agora, aqui, deste lado, os volumes são contrastados em vidro e ferro, altos, pontiagudos, enormes, furando o céu, à procura de compensar Lisboa de não ter já espaço perto e Almada de ver pouco o rio.

Torres enormes ao sol da manhã, torres brilhantes ao sol da tarde, torres de perfis esbeltos, orientadas sobre aquele xadrez vago que antes fora suporte de armazéns e docas, torres violentas como os violentos e enormes navios que encheram a Margueira, com esses soberbos volumes que entraram e saíram durante décadas, habitando essa paisagem de Lisboa, habituando-se à paisagem de Lisboa. 


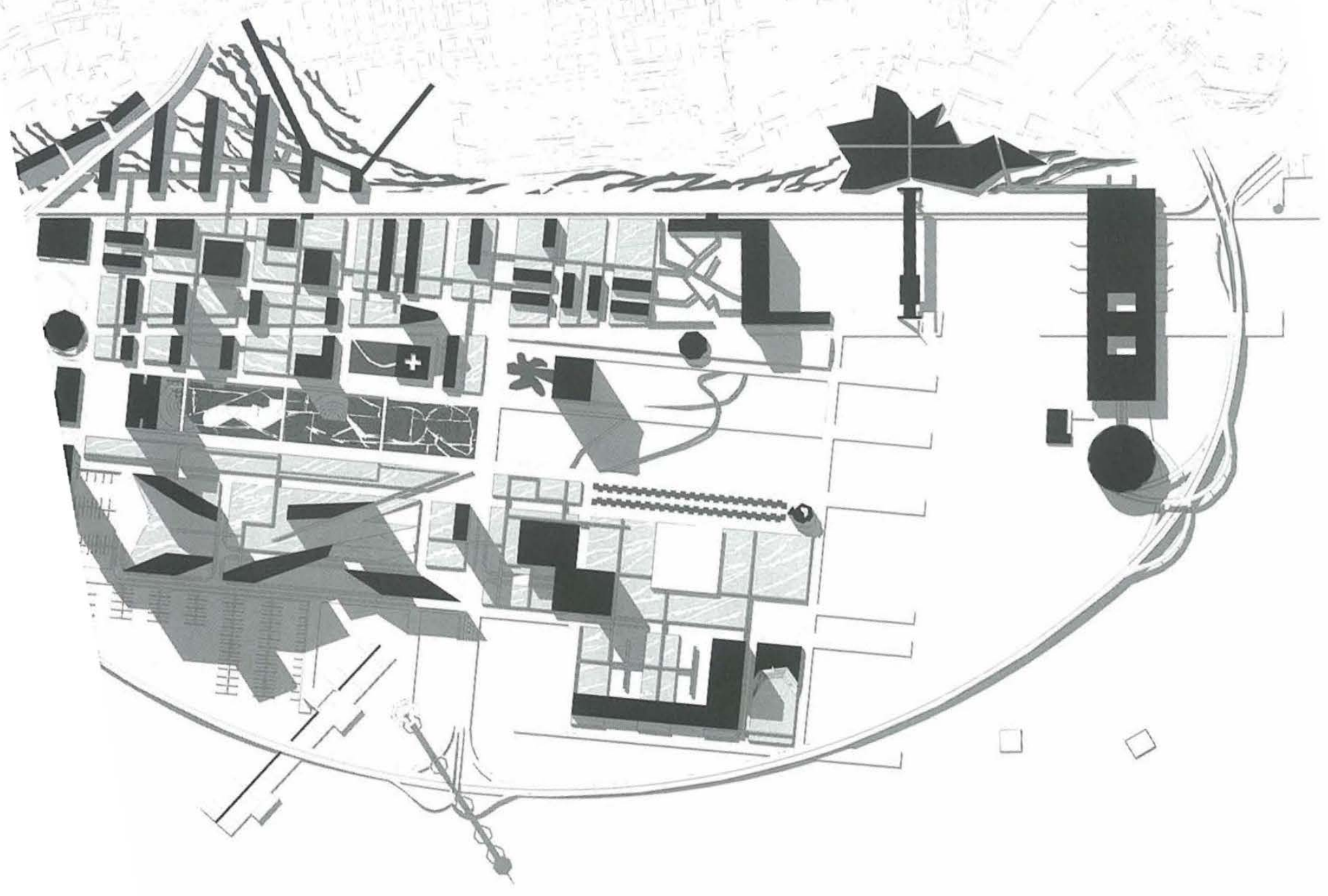

ecd) 800.059 


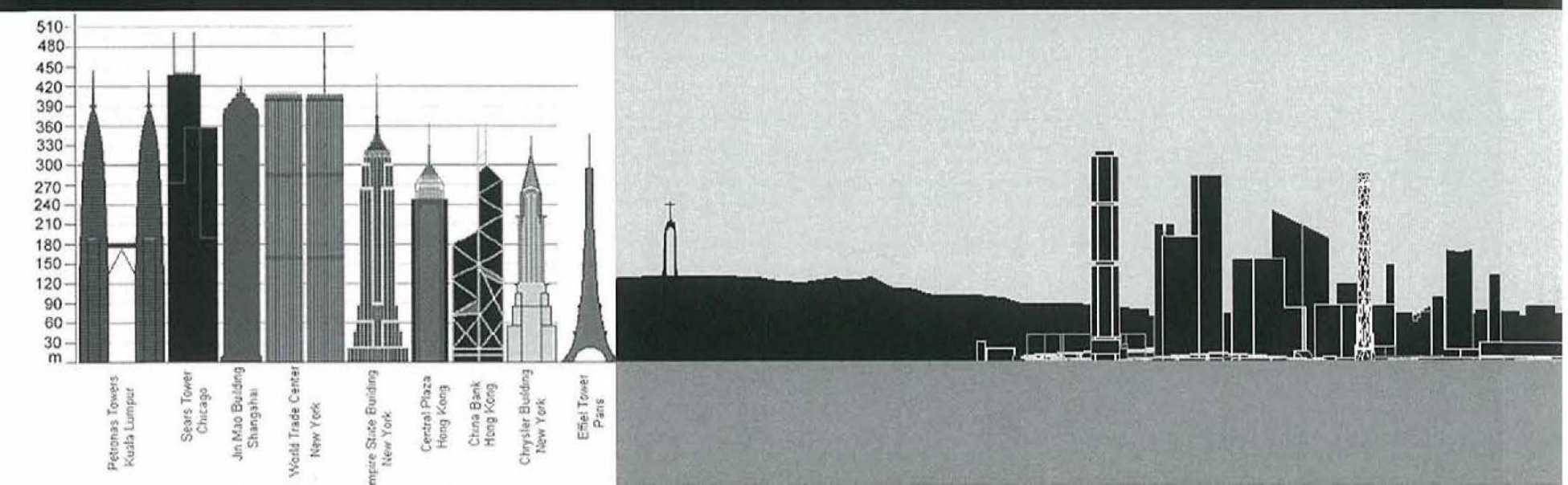


